\title{
THE WILDFOWL TRUST
}

$\mathrm{T}$ HE report* of the Wildfowl Trust for 1957-58 describes the administrative activities of the staff, the state of the accounts (satisfactory), the growth in membership (from 5,094 in 1957 to 5,320 in 1958), the work of scientific members of staff during the year, as well as investigations and observations of wildfowl by many well-known correspondents throughout the world. One of the latter is an interesting account by Eric Fabricius, of the University of Stockholm, of the mechanisms which make plumage waterproof. Fabricius found that ducklings of several species lost their waterproofing on a diet consisting of raw crushed fish, and regained it on a diet of insects; even in specimens that had lost their waterproofing there were indications that the oil gland was functioning.

The oil gland was removed from fourteen young tufted ducks just after hatching, while their down feathers were still enclosed in their isolating horny sheaths. After bursting of these sheaths and the full development of the down, the plumage was as repellent to water as that of the normal control birds, indicating that it is not the secretion of the oil gland which makes the plumage waterproof.

Operated and normal control birds alike lost their waterproofing when subjected to contact with smearing substances. In this condition the barbules of the down foathers were disarranged, sticking together in groups, between which were irregular spaces. The normal waterproofing was gradually restored if the birds were allowed to preen. Plumage remains water-repellent when birds feed on insects because insects are dry and clean. Plumage even remains water-repellent on a diet of fish, provided that the pieces of fish are only given to the birds while these are swimming in clean water. The preening consists of a number of stereotyped movements. The nibbling type of preening movements, in particular, aid in maintaining the barbules in a state which makes the plumage repellent to water. These findings confirm the view of Marsden that the large amount of finely distributed air among the ramifications of the feathers is the principal factor in the water-repellency of plumage.

* Tenth Annual Report of the Wildfowl Trust, 1957-1958. Edited by Peter Scott and Hugh Boyd. Pp. $184+32$ platcs. (Slimbridge, by Peter Scott and Hugh Boyd. Pp. 184+32
Glos.: The Wildfowl Trust, 1959.) 10s. net.
The causes of death of birds at Slimbridge during 1955-57 have been analysed by A. R. Jennings, of the University of Cambridge. Of the $680 \mathrm{birds}$ examined, the largest number of deaths were due to the high incidence of acute pulmonary congestion and pnoumonia among very young birds. Sudden lowering of the air temperature often associated with heavy rainfall brings about this pulmonary syndrome, which is often referred to as 'chilling'. This type of acute respiratory disease is a common cause of high mortality in free-living species, and the same conditions seem to apply even under conditions of semicaptivity. The changes at post-mortem are quite typical and comprise acute congestion and odema of the lungs, an enlarged gall bladder full of viscous bile and usually an unabsorbed yolk sac. In all, 138 birds died from various infections. Aspergillosis was the most frequent with 117 cases, the predilection sites for the fungus boing the lungs and air sacs. The lesions were usually typical fungal granulomata, but in some birds there was an acute diffuse pneumonia. Tuberculosis was the next most common disease, and eight cases were seen.

One of the main objectives of the research programme at Slimbridge has been to obtain a better understanding of the taxonomy of the Anatidx. All the work has now been surveyed by Dr. G. U. T. Matthews, the assistant director of the Trust, who shows that a whole variety of techniques are open to the modern taxonomist. Many of these techniques are incapable of assessing relationships below the family level and are only of passing interest when concerned with relationships within a family. It is beginning to appear that the Anatidæ is an unusually homogeneous and closely knit family.

What makes the report outstanding, of course, is the revealed and hidden imprint of Peter Scott, the director. His sketches lose none of their attractiveness with the years; they may evon excite more interest as they become more audacious. The many photographs are included only if they illustrate the work of the Trust and do so with adornment; not one of them is below standard. With a report of such high quality it is to be hoped that the activities of the Inland Revenue authorities may not, as is feared, lead to the production of future reports in an attenuated form.

\section{DAIRY RESEARCH IN SCOTLAND}

$\mathrm{T}$ HE recent triennial report of the Hannah Dairy Research Institute* gives a clear picture of the expansion of the Institute's activities in the past three years. New laboratories have been built, and greatly increased facilities have been added to those formerly available for metabolic studies. The work reported continues to reflect the aims defined when the Institute was founded some thirty years ago.

Among several important additions to the Institute is a splendidly equipped climatic laboratory. This

* Hannah Dairy Research Institute. Rcport for the Three Years ended March 31,1959 . Pp. 52 . has been constructed, with capital provided by the Colonial Office, and is being used for studies on the effect of climate on the physiology of cattle. The laboratory includes a room in which a cow or steer can be maintained at any temperature from $0^{\circ}$ to $60^{\circ} \mathrm{C}$. within $\pm 0.1^{\circ} \mathrm{C}$., and at a relative humidity within \pm 1 per cent over a wide range. A second room houses four cattle with slightly less critical control of environment. Metabolism houses have also been constructed for sheep and cattle. These contain six new closed-circuit respiration chambers for sheep and one for cattle, and provision is also made for 